\title{
Web-based information on oral dysplasia and precancer of the mouth - quality and readability
}

\author{
Abdullah Alsoghier ${ }^{a, b}$, Richeal Ni Riordain $^{\mathrm{a}}$, Stefano Fedele $^{\mathrm{a}, \mathrm{c}}$, Stephen $_{\text {Porter }}{ }^{\text {* }}$ \\ aUCL Eastman Dental Institute, University College London, London, UK

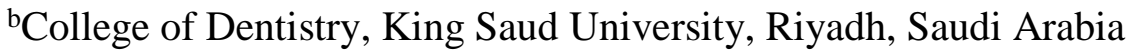 \\ ${ }^{\mathrm{c} N I H R}$ University College London Hospitals, Biomedical Research Centre, London, UK
}

*Corresponding author: Director's Office, UCL Eastman Dental Institute, 256 Gray's Inn Road, London, WC1X 8LD, Tel: +44 (0)20 3456 1038, Fax: +44 (0)20 3456 1039, E-mail: s.porter@ucl.ac.uk

E-mail addresses: a.alsoghier@ucl.ac.uk (A. Alsoghier),r.niriordain@ucl.ac.uk (R. Ni Riordain), s.fedele@ucl.ac.uk (S. Fedele).

\section{Word count:}

3151 words. 
Objectives: The numbers of individuals with oral cancer are increasing. This cancer is preceded by oral epithelial dysplasia (OED). There remains no detailed study of the online information presently available for patients with OED or indeed what information such patients may require to be appropriately informed regarding their condition. Hence, the aim of the present study is to assess the patient-oriented web content with respect to OED.

Methods: The first 100 websites yielded from nine searches performed using different search terms and engines were considered. These were assessed for content, quality (DISCERN instrument, Journal of the American Medical Association benchmarks, and Health on Net seal) and readability (Flesch Reading Ease Score and Flesch-Kincaid Grade Level).

Results: There was a general scarcity of OED content across the identified websites. Information about authors, sources used to compile the publication, treatment, and shared decision were limited or absent. Only $6 \%$ and $27 \%$ of the websites achieved all the four JAMA benchmarks and HON seal, respectively. The average readability level was at 10th grade (US schools), which far exceeds the recommended levels of written health information. Conclusion: At present patients seeking information on OED are likely to have difficulty in finding reliable information from the Web about this disorder and its possible impact upon their life. Further work is thus required to develop a web-based resource regarding OED that addresses the shortfalls demonstrated by the current study.

\section{Keywords:}

Chronic disease

Head and neck neoplasms

Health literacy

Health education

Information seeking behaviour 
Internet

Leukoplakia, oral

Mouth neoplasms

Needs assessment 


\section{Introduction}

Oral epithelial dysplasia (OED) is a histopathological finding associated with an increased risk of malignant transformation of the oral epithelium [1, 2]. The World Health Organisation (WHO) describes dysplasia as an altered epithelium that shows various architectural and cellular changes on the surface epithelial layer as a result of accumulated genetic changes [3]. It is estimated that OED affects $0.25 \%$ to $0.5 \%$ of populations [4]. Clinically, it can present as white, red, or mixed lesion, categorised under the umbrella of oral potential malignant disorders (OPMD), which precede oral cancers in up to $70 \%$ of cases [5].

In 2016, the estimated Internet penetration was at $46 \%$ and $92 \%$ of the world and UK populations respectively [6]. A US population-based survey showed that around $80 \%$ of the web users have searched for online health information $(\mathrm{OHI})$ in the previous year to find information about a medical condition, treatment options, medications, and other topics related to lifestyle [7]. Concerns exist regarding access to online information and also the quality of web-based health information which refers to how reliable, accurate, trustworthy, current [8], and readable the information is. In addition, there may be concerns regarding the subjectivity of commercial bias [9], whether the content is peer reviewed [10], and compliance with rules and regulations [11].

To make the most of their OHI patients require an acceptable level of health literacy. Health literacy empowers individuals by providing the cognitive and social skills needed to 'gain access to, understand and use information in ways which promote and maintain good health' [12]. Those with poor health literacy are believed to have a reduced awareness of their disease process and management as well as limited appreciation of the way health system work. This makes this group at greater risk of poor health, lower quality of life, and higher 
mortality than those with good or high health literacy [13-15]. It is thought that health literacy is associated with general literacy, a term which includes the ability of a person to read, write, speak and problem solve [16]. Therefore a key element of general literacy and in turn health literacy is the readability of the text material. Current evidence indicates that the readability scores of various web-based health information are higher than recommended reading levels [17-22], thus making the currently available potentially incomprehensible and unusable.

There is limited knowledge about the patient-oriented web content with respect to OED. The use of validated assessment instruments could ease the identification of search engines and websites with relevant content, higher quality, and recommended readability levels for written health information. The aim of this study is thus to evaluate the content, quality, and readability of web-based information on OED.

\section{Materials and methods}

Search strategy

Web searches for the terms 'oral dysplasia', 'treatment of oral dysplasia', and 'treatment of precancer of the mouth' was carried out between February and May 2017 using the most commonly employed search engines in the UK: Google.com, Yahoo.com, and Bing.com [23]. For each term, the first 100 websites per search engine were selected with no refinement.

\section{Exclusion criteria}


Links to scientific content (e.g. books or journals), websites that required membership or subscription, websites promoted by search engines, sites that advertise for clinical services or techniques, community-based forums without professional guidance, and websites with only video or audio content were excluded [24, 25].

\section{Content assessment}

The content of the included web sites was assessed following the categorisation method used by Ni Riordain and McCreary [26], which grouped the websites according to affiliation (commercial, non-profit organisation, governmental, or university/medical centre), specialisation (the site is entirely or partly related to the searched topic), content type (medical facts, clinical trials, human interest stories, and question and answer), and content presentation (image, video, and audio).

\section{Quality assessment}

The DISCERN instrument [27], Journal of the American Medical Association (JAMA) benchmarks [28], and Health on the Net (HON) seal [29] were used to evaluate the quality of identified websites. DISCERN is a validated 16-item tool rated by a 5-point scale $(5=$ complete fulfilment of the quality criterion and $1=$ none) that aims to ensure making informed choices based on trusted evidence by evaluating the quality of written health information. It includes questions about the reliability of information (items 1-8), treatment choices (items 9-15), and an overall rating question (item 16). JAMA quality benchmarks ensure the accountability of web-based health information by considering the authorship (authors, their affiliations and credentials), attribution (citations, sources, and copyright), disclosure (acknowledging the ownership, sponsorship, advertising, underwriting, funding and support, and possible conflict of interest), and currency (demonstrate the dates and 
updates) of the given information. $\mathrm{HON}$ is a non-profit foundation that aims to assess the quality and transparency but not the accuracy of web-based health information. HON code of conduct includes eight criteria: authority, complementarity, confidentiality, attribution, justifiability, transparency, financial disclosure, and advertising policy.

\section{Readability assessment}

The readability, described as 'the reading comprehension level a person must have to understand written materials' [30], was assessed using an online tool (https://readable.io) considering two readability formulae: Flesch Reading Ease Score (FRES) [31] and FleschKincaid Grade Level (FKGL) [32]. FRES assesses the readability on a 0-100 scale ( $0=$ hardest and 100=easiest), while FKGL estimates the number of years of education in the US needed to understand a passage of written material. There are no available readability guidelines of the patient-related health information in the UK [33]. Therefore, an approach that considers a range of difficulty as easy $\left(4^{\text {th }}, 5^{\text {th }}\right.$, and $6^{\text {th }}$ grade $)$, average difficulty $\left(7^{\text {th }}, 8^{\text {th }}\right.$ and $9^{\text {th }}$ grade), and difficult (10 ${ }^{\text {th }}$ grade and above) was followed [34].

\section{Data analysis and representation}

The data was collected using a study specific proforma and recorded in Microsoft Excel to facilitate descriptive statistics. The representation of variables was performed by IBM SPSS (version 22.0). To ensure the intra-rater agreement of DISCERN, one of the identified websites was randomly selected and re-assessed by the same investigator (AA), two months after the initial evaluation and the intraclass correlation coefficient (ICC) was determined [25]. Also, the ICC was calculated to ascertain the level of agreement on DISCERN scores between two investigators (AA and RNR) using one randomly selected site. Ethical approval was not required for this study. 


\section{Results}

Only 80 out of 900 websites met the inclusion criteria however 36 sites were considered for the summary evaluation after eliminating the duplicates. The screening results for all searches are summarised in Figure 1. For all searches, Google yielded the highest relevant content to patients, with less non-operating and duplicating links than both of Yahoo! and Bing. Regarding the search terms, "treatment of precancer of the mouth" generated the most relevant websites to patients with all search engines $(n=35)$ followed by 'treatment of oral dysplasia' ( $n=23$ ), and 'oral dysplasia' $(n=20)$. The categorisation of the identified websites is summarised in Table 1.

The quality assessment of the 36 identified websites by DISCERN showed a mean overall rating of $2.24( \pm 0.90)$ out of 5 with no website obtained the highest score (Table 2$)$. The average measure ICC for intra-rater and inter-rater assessment of DISCERN were at 0.789 $[95 \%$ C.I. $=0.419,0.925(P<0.001)]$ and 0.789 [95\% C.I. $=0.403,0.926(P<0.001)]$, respectively. There is no consensus available to interpret the ICC estimate based on $95 \%$ confidence interval, however, a score between 0.75 to 0.90 demonstrates good reliability [35, 36]. HON seal was presented in ten of the identified websites (27\%). The number and percentage of websites per obtained JAMA benchmark are demonstrated in Figure 2. With regard to the total number of benchmarks obtained, four benchmarks were met in 2 websites $(6 \%)$, three benchmarks met in 5 websites (14\%), two benchmarks met in 11 websites (31\%), one benchmark was met in 14 websites (39\%), and no benchmark was found in 4 websites $(10 \%)$ 
With regard to the readability assessment, an analysis with the FKGL showed a range of grade levels from $5^{\text {th }}$ grade to university level $\left(14^{\text {th }}\right.$ grade) with a mean around $10^{\text {th }}$ grade. Using the FRES formula showed a range of scores between 18.1 and 71.9 with a mean of $47.65( \pm 13.63)$. The categorisation of the 36 selected websites based on FRES scores is outlined in Figure 3.

\section{Discussion}

Individuals are motivated to seek health information online in an attempt to seek reassurance, to find alternative opinions on medical interventions and to better comprehend information delivered in the clinical setting [37]. This information-seeking behaviour can aid the 'shareddecision making' model being promoted in healthcare interactions [37]. For example, those affected by OPMD and other potentially malignant conditions frequently use the Internet to obtain information about their condition and treatment options in spite of the potential for unaddressed worries that may arise from the information generated [38]. Although a previous

study noted general acceptability of quality of web-based information of OPMD, no validated assessment tool was used in that study [38]. Also, none of the terms searched in the current analysis were considered in the earlier study.

\section{The content of patient-oriented web information related to OED}

Nine searches were performed in the current study using different terms and search engines to ensure a thorough web analysis of OED. The results indicate that there is a scarcity of patient-oriented web content of OED as only 36 websites of 900 websites were suitable for patients. Other similar studies had a range 50 to 300 websites in their initial assessment [25, 
26, 39-41]. Only 3 of these websites in this study had content specifically devoted to OED with minimal information content in these 3 OED specific sites.

\section{The quality of patient-oriented web information related to OED}

Despite the criticism that DISCERN may not comprehensively assess the web content when compared to JAMA benchmarks, a previous study noted its satisfactory internal consistency and inter-rater reliability [42]. The mean of overall rating by DISCERN was at 2.42 out of 5 which is similar to other studies of oral leukoplakia (2.3) [39] and head and neck cancer (2.55) [26]. As with previous studies, questions concerning sources to compile the publication [41] as well as those related to the risks of each treatment, effects of treatment choice on quality of life, and support for shared decision-making [39] had notably low mean scores. Like the findings of DISCERN, the JAMA benchmarks, authorship, attribution, and currency, were only achieved in around one-third of the identified websites - which is low compared to head and neck cancer $(66 \%, 69 \%$, and $84 \%$ respectively) [26], oral leukoplakia (50\% of each) [39] but similar to the findings reported with oral ulcers $(27 \%, 33 \%$, and $61 \%$ respectively) [41]. Given that a website failing to fulfil a minimum of three of these criteria might be considered as suspicious [28] - 80\% of the websites included in this analysis would fall in this category. Due to the lack of JAMA benchmarks achieved the information on the majority of these sites may not be trustworthy and may therefore set unrealistic expectations regarding treatment interventions. This could then perhaps adversely influence the patients' ability to make autonomous and informed decisions [39, 43, 44].

Although HON was introduced in 1995, its application is still limited, perhaps due to a lack of awareness of its existence by designers of health information websites. In addition, the certification process can take up to 14 weeks [29] and thus may serve as a deterrent to usage. 
This was possibly evident in our study as only $27 \%$ of the analysed websites have maintained the HON code seal a rate however that is higher compared to adult orthodontics at $2 \%$ [25], oral ulceration at $7 \%$ [41], and oral leukoplakia at 17\% [39]. Nonetheless, it is important to note that organisations such as the NHS have developed a more sophisticated quality mark called Information Standard, which was not considered in this study due to its very recent introduction [45].

\section{The readability of patient-oriented web information related to $O E D$}

Both FRES and FKGL indices used in the present analysis measure the readability by using the word and sentence length but with different formulae. The present analyses showed that only users who at or above $10^{\text {th }}$ grade (US schools) might be likely to comprehend the content of the websites. These levels far exceeded those recommended by the American Medical Association (AMA) for written patient education materials which are at $5^{\text {th }}$ to $6^{\text {th }}$ grade levels or even lower in practices attended by individuals with expected lower literacy [46]. Achieving these recommendations is necessary to enable all readers with different literacy levels to comprehend the information and to enhance the informed decisions about their conditions [25].

\section{The role of information provision in the management of chronic disease such as OED}

Living with a chronic and potentially malignant disease such as OED often requires effective health behaviour changes, which necessitate that an individual has an awareness of their disease and is provided with the information and skills necessary to initiate and maintain these behaviour changes [47]. The most important modifiable risk factors for oral cancer are tobacco, excessive alcohol consumption and the use of betel quid [48]. Numerous studies have evaluated the impact of online interventions to change health behaviours including 
disease management and tobacco smoking cessation $[49,50]$. When considering smoking cessation specifically, online interventions are considered to have the potential to increase cessation rates thereby having a positive influence on a key modifiable risk factor in patients with potentially malignant oral disease.

There is limited knowledge of the psychological impact of oral cancer symptoms upon affected individuals [51]. Individuals with other suspected cancer conditions (e.g. breast, lung, and colorectal structures) reported negatively affected quality of life and high levels of anxiety at the pre-diagnostic phase that can remain despite having a later benign outcome [52-54]. The possible reasons why the diagnosis of OED may cause distress may include the perception of threat to life, experienced symptoms including pain and disability, and treatment and its effects on physical and psychosocial well-being. Thus, providing tailored information for patients with longstanding conditions such as OED must acknowledge their information needs and considering the impact of the illness and its treatment on physical and psychological well-being [55-57]. One evolving method is to acquire these aspects by patient-based information needs assessment scales. There are tools available for various chronic disorders, but none of these are known to be suitable to assess the need for information for OED specifically.

\section{Available information on oral dysplasia at health speciality organisations}

Since health professional organisations are regarded as reliable sources for health information to patients and public [9], the relevant societies were searched deliberately and a patient information leaflet of OED found at British Society of Oral Medicine (BSOM) website [58]. This leaflet showed good quality by achieving an overall rating of four out of 5 by DISCERN and obtained three out of four JAMA benchmarks. However, it did not provide information 
about making informed decisions or what sources of information were employed to compile the leaflet. Similarly, the information about how the treatment works, its benefits or risks, and its effect on quality of life was not detailed. Also, its FRES score was at 51 which is fairly difficult to read. Another section about premalignant oral lesions, which was included in the analysis of the current study, is presented on the American Academy of Oral Medicine website [59]. This section obtained a good overall rating by DISCERN (4 out of five) but achieved only 2 out of the 4 JAMA benchmarks (authorship and disclosure). Its readability level was difficult to read (FRES $=45$ ) which is similar to findings from other studies [46]. Through partnerships with medical practices and health speciality organisations, clinicians should consider the imperfections addressed by the current study, acknowledge better the published literature and create credible and user-friendly written health materials to patients and the public $[15,46]$. There is also perhaps a need to improve the searching algorithms by Web search engines [9] to ensure finding reliable information sources if other descriptions of OED are being searched (e.g. oral precancer or oral potential malignant disorders).

\section{Patient support groups as a supplementary source of valid and reliable information}

Patient support groups can be valuable in patient education by providing a source of informational support, first-hand experience, and positively impacting upon changing an individual's s attitude toward their chronic illness [58, 60] and precancerous disease [61]. Further to the advantages of face-to-face support groups, online support groups have been extensively developed for numerous conditions to improve access to helpful sources, overcome geographical and time restraints, and yet ensure anonymity [62, 63]. In dental health care, these groups can provide a supportive atmosphere to share previous experiences and concerns about dental management and motivation to dental attendance, particularly across dentally anxious individuals $[64,65]$. Anxiety and fear may act as a barrier from 
attending regular clinic visits [64] and therefore such motivation is necessary especially when it comes to reporting worrying symptoms (e.g. change in appearance or size) of OED to the dental practitioner.

Examples of English language websites providing online support groups that can be suitable for patients with OED include disease-related online support groups such as UK Lichen Planus (https://www.uklp.org.uk) International OLP Support Group (https://dentistry.tamhsc.edu/olp), Lupus Foundation of America (https://www.lupus.org), and rare disease support groups that can be searched at the National Organisation for Rare Disease website (https://rarediseases.org). Other available online sources include cancer [e.g. Mouth Cancer Foundation (http://mouthcancerfoundation.org), Oral Cancer Foundation (https://oralcancerfoundation.org), and Cancer Survivors Network by American Medical Association (https://csn.cancer.org)] as well as alcohol/smoking cessation support groups [e.g. Smokers' Helpline by Canadian Cancer Society (https://www.smokershelpline.ca) and Alcoholics Anonymous (https://www.aa.org)]. Despite its advantages over face-to-face support groups [66], concerns remain toward the accuracy of shared information via online support groups as well as the cost of access to the Internet and shortage of professional facilitators $[67,68]$.

\section{The limitations and strengths of the study}

Aside from limitations of each assessment tool, this study is limited by restricting the search to English websites at a one-time point and considering the initial page of each link. Although $77 \%$ of OHI seekers in the US begin the search for information using a search engine, it is important to consider other sources such as general websites (e.g. Wikipedia), medical information websites (e.g. WebMD), social network sites (e.g. Facebook) [7] as well 
as mobile health applications [69]. Strengths include conducting nine searches of different search engines and terms as well as using more than one assessment tool per criteria (i.e. quality and readability) compared with previous studies that used a single method of each criteria $[10,40,70]$.

\section{Conclusion}

The available web-based information on OED has little content specifically relating to OED and is generally of low quality. The readability scores, as shown by FRES and FKGL, are well above the recommended levels for written health materials. Thus at present patients seeking online information on OED are likely to have difficulty in finding and understanding reliable information about such disease and its possible impact upon their life. Further work is required to generate a web-based resource for OED that addresses the shortfalls demonstrated by the current study.

\section{Funding}

This research did not receive any specific grant from funding agencies in the public, commercial, or not-for-profit sectors. AA held a studentship grant from King Saud University, Saudi Arabia during the current study. 


\section{References}

[1] Ho MW, Risk JM, Woolgar JA, Field EA, Field JK, Steele JC, et al. The clinical determinants of malignant transformation in oral epithelial dysplasia. Oral Oncol. 2012;48:969-76.

[2] Sarode SC, Sarode GS, Tupkari JV. Oral potentially malignant disorders: A proposal for terminology and definition with review of literature. J Oral Maxillofac Pathol 2014;18:S77S80.

[3] El-Naggar AK, Chan JKC, Grandis JR, Takata T, Slootweg PJ. WHO classification of head and neck tumours. 4th ed. Lyon, France:: International Agency for Research on Cancer (IARC); 2017. p. 112-5.

[4] Mehanna HM, Rattay T, Smith J, McConkey CC. Treatment and follow-up of oral dysplasia - a systematic review and meta-analysis. Head Neck. 2009;31:1600-9.

[5] Jin LJ, Lamster IB, Greenspan JS, Pitts NB, Scully C, Warnakulasuriya S. Global burden of oral diseases: emerging concepts, management and interplay with systemic health. Oral Dis. 2016;22:609-19.

[6] InternetLiveStats.com. Internet Users. 2017.

[7] Fox S, Duggan M. Health Online 2013. Washington: Pew Research Center; 2013. p. 3-5. [8] Magunacelaya MB, Glendor U. Surfing for mouth guards: assessing quality of online information. Dent Traumatol 2011;27:334-43.

[9] Dy CJ, Taylor SA, Patel RM, Kitay A, Roberts TR, Daluiski A. The effect of search term on the quality and accuracy of online information regarding distal radius fractures. J Hand Surg Am. 2012;37:1881-7.

[10] Sacchi M, Yeung TM, Spinelli A, Mortensen NJ. Assessment of the quality of patientorientated internet information on surgery for ulcerative colitis. Colorectal Dis 2015;17:5114. 
[11] Nichols LC, Hassall D. Quality and content of dental practice websites. Br Dent J. 2011;210:E11-E.

[12] Nutbeam D. Health promotion glossary. Health Promot Int 1998;13:349-64.

[13] Merriman B, Ades T, Seffrin JR. Health Literacy in the Information Age:

Communicating Cancer Information to Patients and Families. CA Cancer J Clin. 2002;52:130-3.

[14] Davis TC, Williams MV, Marin E, Parker RM, Glass J. Health literacy and cancer communication. CA Cancer J Clin. 2002;52:134-49.

[15] McInnes N, Haglund BJ. Readability of online health information: implications for health literacy. Inform Health Soc Care. 2011;36:173-89.

[16] Office of Disease Prevention and Health Promotion. Health Literacy Online: A guide to simplifying the user experience. 2nd ed. USA: U.S. Department of Health and Human Services; 2015.

[17] Sanghvi S, Cherla DV, Shukla PA, Eloy JA. Readability assessment of internet-based patient education materials related to facial fractures. Laryngoscope. 2012;122:1943-8. [18] Walsh TM, Volsko TA. Readability assessment of internet-based consumer health information. Respir Care. 2008;53:1310-5.

[19] AlKhalili R, Shukla PA, Patel RH, Sanghvi S, Hubbi B. Readability assessment of internet-based patient education materials related to mammography for breast cancer screening. Acad Radiol. 2015;22:290-5.

[20] Vives M, Young L, Sabharwal S. Readability of spine-related patient education materials from subspecialty organization and spine practitioner websites. Spine. 2009;34:2826-31.

[21] Roberts H, Zhang D, Dyer GS. The Readability of AAOS Patient Education Materials: Evaluating the Progress Since 2008. J Bone Joint Surg Am. 2016;98:e70. 
[22] Park A, Zhu SH, Conway M. The Readability of Electronic Cigarette Health Information and Advice: A Quantitative Analysis of Web-Based Information. JMIR Public Health Surveill. 2017;3:e1.

[23] Alexa.com. Top Sites in United Kingdom. 2017.

[24] Jayaratne YS, Anderson NK, Zwahlen RA. Readability of websites containing information on dental implants. Clin Oral Implants Res. 2014;25:1319-24.

[25] McMorrow SM, Millett DT. Adult orthodontics: a quality assessment of Internet information. J Orthod. 2016;43:186-92.

[26] Ni Riordain R, McCreary C. Head and neck cancer information on the internet: type, accuracy and content. Oral Oncol. 2009;45:675-7.

[27] Charnock D. The DISCERN handbook : quality criteria for consumer health information on treatment choices. Abingdon, Oxon: Radcliffe Medical Press 1998. p. 51.

[28] Silberg WM, Lundberg GD, Musacchio RA. Assessing, controlling, and assuring the quality of medical information on the Internet: Caveant lector et viewor--Let the reader and viewer beware. J Amer Med Assoc. 1997;277:1244-5.

[29] Health on the Net Foundation. HONcode section for medical professionals 2017.

[30] Albright J, de Guzman C, Acebo P, Paiva D, Faulkner M, Swanson J. Readability of patient education materials: implications for clinical practice. Appl Nurs Res. 1996;9:139-43. [31] Flesch R. A new readability yardstick. J Appl Psychol. 1948;32:221-33.

[32] Kincaid JP, Fishburne Jr RP, Rogers RL, Chissom BS. Derivation of new readability formulas (automated readability index, fog count and flesch reading ease formula) for navy enlisted personnel. DTIC Document; 1975.

[33] Fitzsimmons PR, Michael BD, Hulley JL, Scott GO. A readability assessment of online Parkinson's disease information. J R Coll Physicians Edinb. 2010;40:292-6. 
[34] U.S. Department of Health and Human Services. Using Readability Formulas: A Cautionary Note, in Toolkit for Making Written Material Clear and Effective. Baltimore, MD: Centers for Medicare \& Medicaid Services; 2010.

[35] Koo TK, Li MY. A Guideline of Selecting and Reporting Intraclass Correlation Coefficients for Reliability Research. J Chiropr Med. 2016;15:155-63.

[36] Weir JP. Quantifying test-retest reliability using the intraclass correlation coefficient and the SEM. J Strength Cond Res. 2005;19:231-40.

[37] Powell J, Inglis N, Ronnie J, Large S. The characteristics and motivations of online health information seekers: cross-sectional survey and qualitative interview study. J Med Internet Res. 2011;13:e20.

[38] Alcaide-Raya A, Hughes R, Warnakulasuriya S. How well informed are our Internet savvy patients on oral premalignant disorders? Oral Surg. 2010;3:120-28.

[39] Wiriyakijja P, Fedele S, Porter S, Ni Riordain R. Web-based information on the treatment of oral leukoplakia - quality and readability. J Oral Pathol Med. 2016;45:617-20. [40] Aldairy T, Laverick S, McIntyre GT. Orthognathic surgery: is patient information on the Internet valid? Eur J Orthod. 2012;34:466-9.

[41] Ni Riordain R, Hodgson T. Content and quality of website information on the treatment of oral ulcers. Br Dent J. 2014;217:E15.

[42] Ademiluyi G, Rees CE, Sheard CE. Evaluating the reliability and validity of three tools to assess the quality of health information on the Internet. Patient Educ Couns. 2003;50:1515. [43] Stairmand J, Signal L, Sarfati D, Jackson C, Batten L, Holdaway M, et al. Consideration of comorbidity in treatment decision making in multidisciplinary cancer team meetings: a systematic review. Ann Oncol. 2015;26:1325-32. 
[44] Braddock CH, 3rd, Edwards KA, Hasenberg NM, Laidley TL, Levinson W. Informed decision making in outpatient practice: time to get back to basics. J Amer Med Assoc. $1999 ; 282: 2313-20$.

[45] NHS England. The Information Standard Principles. 2017.

[46] Weiss BD. Health literacy and patient safety: Help patients understand. Manual for clinicians. 2nd ed. Chicago, I: American Medical Association Foundation 2007. p. 38-9. [47] Schwarzer R, Fuchs R. Changing risk behaviors and adopting health behaviors: The role of self-efficacy beliefs. In: Bandura A, editor. Self-Efficacy in Changing Societies. Cambridge: Cambridge University Press; 1995. p. 259-88.

[48] Warnakulasuriya S. Living with oral cancer: epidemiology with particular reference to prevalence and life-style changes that influence survival. Oral Oncol. 2010;46:407-10. [49] Portnoy DB, Scott-Sheldon LAJ, Johnson BT, Carey MP. Computer-delivered interventions for health promotion and behavioral risk reduction: a meta-analysis of 75 randomized controlled trials, 1988-2007. Prev Med. 2008;47:3-16.

[50] Strecher VJ. Computer-tailored smoking cessation materials: a review and discussion. Patient Educ Couns. 1999;36:107-17.

[51] Noonan B. Understanding the reasons why patients delay seeking treatment for oral cancer symptoms from a primary health care professional: An integrative literature review. Eur J Oncol Nurs. 2014;18:118-24.

[52] Brocken P, van der Heijden EH, Oud KT, Bootsma G, Groen HJ, Donders AR, et al. Distress in suspected lung cancer patients following rapid and standard diagnostic programs: a prospective observational study. Psychooncology. 2015;24:433-41.

[53] Brocken P, Prins JB, Dekhuijzen PNR, van der Heijden HFM. The faster the better?-A systematic review on distress in the diagnostic phase of suspected cancer, and the influence of rapid diagnostic pathways. Psychooncology 2012;21:1-10. 
[54] Ndukwe N, Borowski DW, Lee A, Orr A, Dexter-Smith S, Agarwal AK. The two-week rule for suspected colorectal cancer: patient experience and psychological impact. Int $\mathbf{J}$ Health Care Qual Assur. 2012;25:75-85.

[55] Luker KA, Beaver K, Leinster SJ, Owens RG, Degner LF, Sloan JA. The information needs of women newly diagnosed with breast cancer. J Adv Nurs. 1995;22:134-41.

[56] Foster C, Myall M, Scott I, Sayers M, Brindle L, Cotterell P, et al. 'You can't say, "what about me?" I'm not the one with cancer': information and support needs of relatives.

Psychooncology. 2015;24:705-11.

[57] Kassianos AP, Raats MM, Gage H. An Exploratory Study on the Information Needs of Prostate Cancer Patients and Their Partners. Health Psychol Res. 2016;4:4786.

[58] BSOM. Oral Epithelial Dysplasia. 2016.

[59] AAOM. Premalignant Oral Lesions. 2008.

[60] Helgeson VS, Cohen S, Schulz R, Yasko J. Group support interventions for women with breast cancer: who benefits from what? Health psychology. 2000;19:107.

[61] Sugerman PB, Sabage NW. Oral lichen planus: causes, diagnosis and management. Australian dental journal. 2002;47:290-7.

[62] Bartlett YK, Coulson NS. An investigation into the empowerment effects of using online support groups and how this affects health professional/patient communication. Patient education and counseling. 2011;83:113-9.

[63] Wright KB, Bell SB, Wright KB, Bell SB. Health-related support groups on the Internet: Linking empirical findings to social support and computer-mediated communication theory. Journal of Health Psychology. 2003;8:39-54.

[64] Eijkman M. A fearful patient's journey for dental help. Elsevier; 2007. 
[65] Buchanan H, Coulson NS. Accessing dental anxiety online support groups: An exploratory qualitative study of motives and experiences. Patient education and counseling. 2007;66:263-9.

[66] Scott CR. Communication technology and group communication. The handbook of group communication theory and research. 1999:432-72.

[67] Coulson NS, Buchanan H, Aubeeluck A. Social support in cyberspace: a content analysis of communication within a Huntington's disease online support group. Patient education and counseling. 2007;68:173-8.

[68] Klemm P, Reppert K Fau - Visich L, Visich L. A nontraditional cancer support group. The Internet.

[69] IMS Institute. Patient Adoption of mHealth: Use, Evidence and Remaining Barriers to Mainstream Acceptance. Parsippany, NJ, USA: IMS Institute for Healthcare Informatics; 2015. p. 1-4.

[70] Dy CJ, Taylor SA, Patel RM, McCarthy MM, Roberts TR, Daluiski A. Does the quality, accuracy, and readability of information about lateral epicondylitis on the internet vary with the search term used? Hand (New York, NY). 2012;7:420-5. 
Figure 1 A summary of results for all searches.

Figure 2 The JAMA benchmarks achieved by number and percentage of the 36 identified websites.

Figure 3 The number of websites per reading easiness grade based on Flesch Reading Ease Scores $(n=36)$. 
Table 1

Summary of categorisation of the analysed websites according to affiliation, specialisation, and content type $(n=36)$.

\begin{tabular}{clc}
\hline Category & \multicolumn{1}{c}{ Criteria } & $\begin{array}{c}\text { Number of } \\
\text { websites (\%) }\end{array}$ \\
\hline Affiliation & Commercial & $12(33.33 \%)$ \\
& Non-profit organisation & $12(33.33 \%)$ \\
& $\begin{array}{l}\text { Governmental } \\
\text { University/medical centre }\end{array}$ & $11(3.77 \%)$ \\
& Specialisation & Site is entirely related to \\
& oral precancer & $6(16.66 \%)$ \\
& Site is partially related to & $30(83.33 \%)$ \\
& oral precancer & \\
\hline \multirow{2}{*}{ Content type } & Medical facts & $30(83.33 \%)$ \\
& Clinical trials & $2(5.55 \%)$ \\
& Human interest stories & $2(5.55 \%)$ \\
& Question and answer & $17(47.22 \%)$ \\
\hline \multirow{2}{*}{ pontent } & Image & $19(52.77 \%)$ \\
& Video & $1(2.77 \%)$ \\
& Audio & $1(2.77 \%)$ \\
& & \\
\hline
\end{tabular}


Table 2

The mean DISCERN scores of the 36 selected websites.

\begin{tabular}{llc}
\hline Domain & \multicolumn{1}{c}{ DISCERN question } & $\begin{array}{c}\text { Mean score } \\
\text { (Std. Deviation) }\end{array}$ \\
\hline Reliability & Q1. Explicit aims & $3.56( \pm 0.80)$ \\
& Q2. Attainment of aims & $3.19( \pm 1.16)$ \\
& Q3. Relevance & $3.89( \pm 0.91)$ \\
& Q4. Explicit sources & $1.86( \pm 1.22)$ \\
& Q5. Explicit date & $2.31( \pm 1.30)$ \\
& Q6. Balanced and unbiased & $2.97( \pm 1.02)$ \\
& Q7. Additional sources & $2.47( \pm 1.46)$ \\
& Q8. Areas of uncertainty & $3.08( \pm 1.18)$ \\
\hline Treatment & Q9. How treatment works & $2.25( \pm 1.15)$ \\
options & Q10. Benefits of treatment & $2.14( \pm 1.07)$ \\
& Q11. Risk of treatment & $1.97( \pm 1.08)$ \\
& Q12. Effects of no treatment & $2.22( \pm 1.09)$ \\
& Q13. Effects on quality of life & $1.92( \pm 1.10)$ \\
& Q14. All alternatives described & $3.00( \pm 1.58)$ \\
& Q15. Shared decision & $1.86( \pm 1.17)$ \\
\hline Overall & & $2.42( \pm 0.90)$ \\
rating & & \\
\hline
\end{tabular}




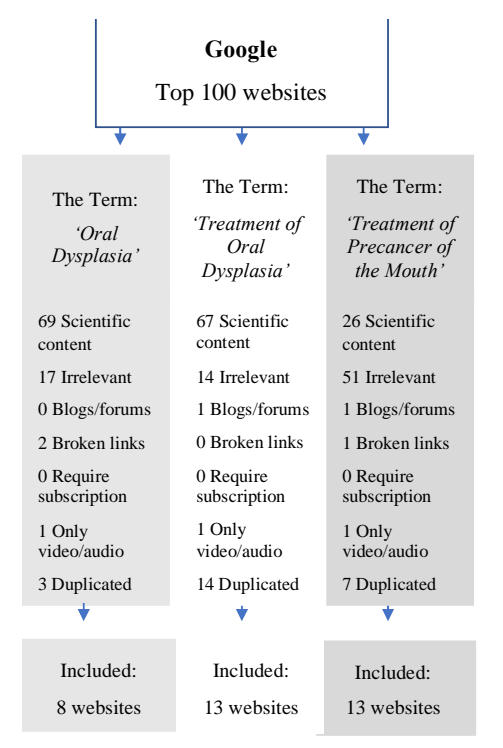

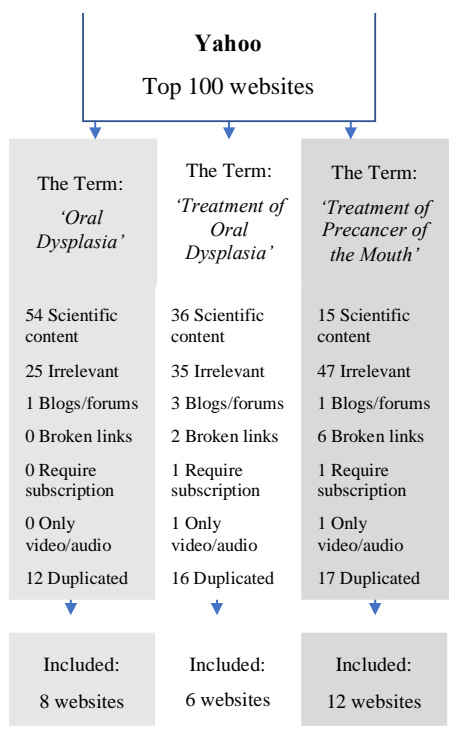

\begin{tabular}{|c|c|c|}
\hline \multicolumn{2}{|c|}{$\begin{array}{c}\text { Bing } \\
\text { Top } 100 \text { websites }\end{array}$} & \\
\hline$\downarrow$ & $\downarrow$ & $\downarrow$ \\
\hline The Term: & The Term: & The Term: \\
\hline $\begin{array}{c}\text { 'Oral } \\
\text { Dysplasia' }\end{array}$ & $\begin{array}{l}\text { 'Treatment of } \\
\text { Oral } \\
\text { Dysplasia' }\end{array}$ & $\begin{array}{l}\text { 'Treatment of } \\
\text { Precancer of } \\
\text { the Mouth' }\end{array}$ \\
\hline $\begin{array}{l}49 \text { Scientific } \\
\text { content }\end{array}$ & $\begin{array}{l}34 \text { Scientific } \\
\text { content }\end{array}$ & $\begin{array}{l}10 \text { Scientific } \\
\text { content }\end{array}$ \\
\hline 37 Irrelevant & 37 Irrelevant & 62 Irrelevant \\
\hline $0 \mathrm{Blogs} /$ forums & $2 \mathrm{Blogs} /$ forums & $1 \mathrm{Blogs} /$ forums \\
\hline 1 Broken links & 2 Broken links & 1 Broken links \\
\hline $\begin{array}{l}0 \text { Require } \\
\text { subscription }\end{array}$ & $\begin{array}{l}1 \text { Require } \\
\text { subscription }\end{array}$ & $\begin{array}{l}0 \text { Require } \\
\text { subscription }\end{array}$ \\
\hline $\begin{array}{l}0 \text { Only } \\
\text { video/audio }\end{array}$ & $\begin{array}{l}\text { 0 Only } \\
\text { video/audio }\end{array}$ & $\begin{array}{l}1 \text { Only } \\
\text { video/audio }\end{array}$ \\
\hline 9 Duplicated & 18 Duplicated & 15 Duplicated \\
\hline$\downarrow$ & $\downarrow$ & $\downarrow$ \\
\hline $\begin{array}{l}\text { Included: } \\
4 \text { websites }\end{array}$ & $\begin{array}{l}\text { Included: } \\
6 \text { websites }\end{array}$ & $\begin{array}{l}\text { Included: } \\
10 \text { websites }\end{array}$ \\
\hline
\end{tabular}


$80 \%$

$70 \%$

$60 \%$

$50 \%$

$40 \%$

$30 \%$

$20 \%$

$10 \%$

$0 \%$

Authorship $(n=10)$ Attribution $(n=10)$ Disclosure $(n=26) \quad$ Currency $(n=13)$ 


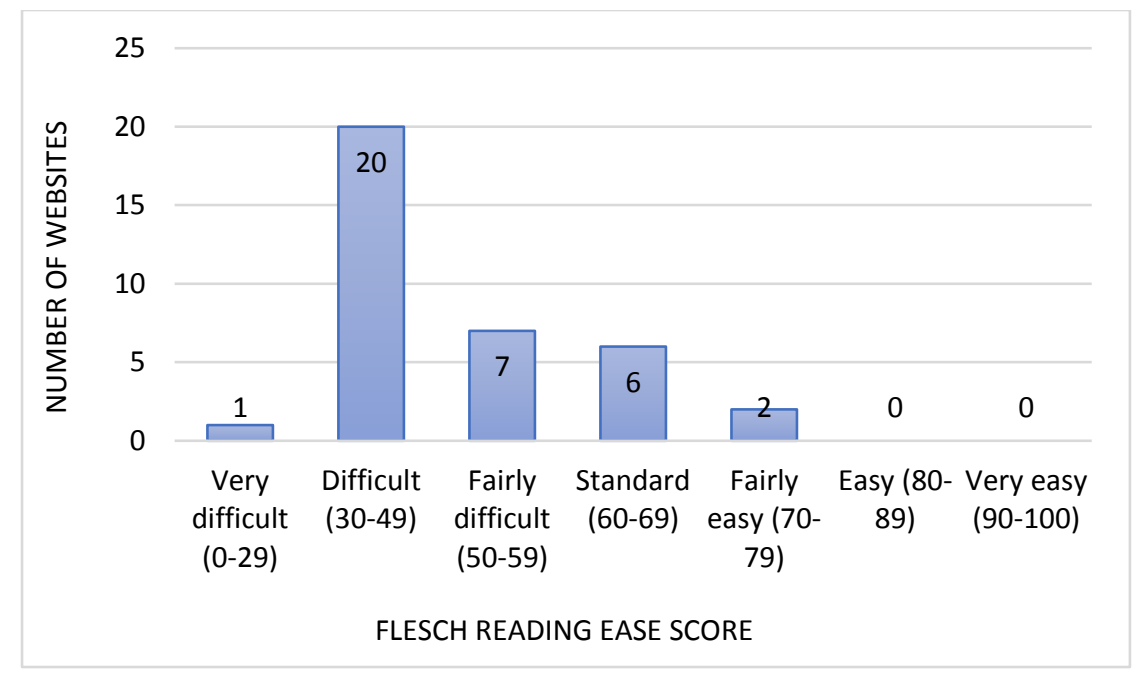

